\title{
Collaboration with Foreign Universities for Innovation: Evidence from Chinese Manufacturing Firms
}

\author{
Xiaolan $\mathrm{Fu}^{*}$ \\ Department of International Development, University of Oxford; Oxford, UK \\ Jizhen Li \\ School of Management and Economics, Tsinghua University, Beijing, China
}

\begin{abstract}
While prior research has focused upon the role of university-industry linkage in the promotion of innovation, there has been little research distinguishing the different roles of domestic and foreign universities in this pursuit. This paper explores the different impacts of domestic and foreign universities on innovation performance in emerging economies using a national firm-level survey database from China. It finds that international innovation collaboration with leading universities in other developing countries, especially with those in the Newly Industrialised Economies (NIEs) and the emerging South, is fruitful in enhancing the creation of ground-breaking innovations in indigenous Chinese firms. In contrast, the contribution of universities in the US/EU/Japan is significantly beneficial to foreigninvested firms. Collaboration with domestic universities has played a significant role in the diffusion of advanced technology in China.
\end{abstract}

Key words: Innovation, International collaboration, university-industry linkage, China 


\section{Introduction}

As an important player in national and regional innovation systems, universities are widely regarded as a major contributor to advances in basic scientific research and industrial innovation. However, most of the received wisdom on the role of universities is based on experience and evidence from developed countries (eg. Etzkowitz, 2002; and Gulbrandsen, et al., 2011). Our understanding is still limited with regard to the effects of a university-industry collaboration (UIC) on imitative and ground-breaking novel innovations in emerging economies. Moreover, innovation is increasingly a collaborative and global undertaking due to the internationalisation of innovation and changes in innovation mode from closed to open. Firms in emerging economies have started to collaborate not only with domestic universities but also with foreign universities. It is hence important to understand different roles of domestic and foreign universities in industrial innovation in emerging economies, especially in their pursuit of catch-up and upgrading.

This research attempts to fill in these gaps in the literature by examining the role of intra- and international UIC in novel and imitative innovations in emerging economies using firm-level data from China. China provides a good case study for this research for several reasons. First, China is one of the major emerging economies in the world. It is attempting to develop a path of compressed development and leapfrog the conventional latecomer path of imitative industrialisation and progression up the value chain. Second, the industrial and university sectors in China have made impressive progress in innovation since the reforms of 1978. In 2010, total Research and Development (R\&D) expenditure in China ranked the third in the world. Thirdly, the Chinese government has made great efforts to foster university-industry linkage and to encourage technology transfer (Wu, 2007; OECD, 2008). So, China is a good case for research on the role of universities in industrial innovation in emerging economies. 
The research contributes to the literature in three ways. First, most of the research on universityindustry innovation collaboration has not distinguished collaboration with foreign and domestic universities. In the globalisation era, firms are increasingly open and internationalised in their R\&D activities. It is hence important to understand the effect of such international university-industry collaborations. To our knowledge, this is the first research that distinguishes effects of foreign from domestic universities in innovation collaboration. This is one of the rare research projects that explores the contribution of international collaboration to innovation, as well as the moderating roles of cultural differences and geographic, technical and institutional distances in shaping the collaboration outcome. Second, it deepens on our understanding of the role of a UIC in the middleincome emerging economies given different effects of UIC on novel and imitative innovations. We have to take account of various demands and motivations for university-industry linkage and diverse capabilities in the industrial and university sectors at different development stages. Finally, the paper provides the first empirical evidence of the role of universities in emerging economies based on a large national firm-level survey dataset.

The remainder of the paper is organised as follows. Section 2 discusses the literature and the theoretical framework. Section 3 discusses the methodology and data. Section 4 presents the results. Section 5 concludes.

\section{The literature and the hypotheses}

The literature on national innovation systems has highlighted the role of universities, not only in training and education, but also as an active player in knowledge creation and transfer (Braczyk et al, 1998; OECD, 2008). They disseminate knowledge to the real economy by producing quality students and by interacting with firms through a number of channels such as consulting, licensing, and collaborative research projects (Eom and Lee, 2010). The emergence of open innovation as a new 
mode of innovation suggests that universities may play a more important role in industrial innovation, as external knowledge sources and co-producers of new products and processes. Firms adopt open innovation to tap into external resources and talents, share uncertainties, diversify risks and promote learning (Chesbrough, 2003; Keupp and Gassmann, 2009). Universities also facilitate the attainment of complementary assets and allow firms to achieve goals which they cannot pursue alone (Mowery, et al., 1996; Powell and Grodal, 2005). As a result, firms networking with others are found to have greater innovative performance (Goes and Park, 1997; Tsai, 2001; Laursen and Salter, 2006). In recent years, open innovation has not only been adopted rapidly at the firm level but also emerged at the system level as an open regional innovation system if firms are open to external-tothe-region research networks and knowledge sources (Belussi, et al., 2010).

Given these trends, a growing number of the countries are seeking to use universities as an important driver of knowledge-based economic development and technical change (Mowery and Sampat, 2005). Through interaction with the science base, firms are able to access a diversified range of knowledge sources in comparison to intra-firm collaboration (Kaufmann and Todtling, 2001), especially in relation to tacit and uncodified knowledge (Yusuf, 2008). Learning organisations create important assets in the form of codified (e.g., publications, patents, contract R\&D projects) and tacit (e.g., collaborative research, informal consultation) knowledge and transfer them to firms (Kodama, et al., 2008). In sum, there is a gathering belief that contracting out research to universities and collaborating with universities can confer substantial advantages and hence offer a new vehicle for catch-up (Lee, et al., 2009). 'Bridging researchers' from universities are also found to be an effective link to bring international sciences to domestic industry (Giuliani and Rabellotti, 2012).

\subsection{Motivations, capabilities, heterogeneity of knowledge and the role of foreign universities}


The impact of a UIC on innovation outcomes depends on the motivations and capabilities of both parties. These factors first affect a partner's willingness to engage in a UIC (Lai, 2011). Firms collaborate with universities for different reasons - from paradigm shifting to technical problemsolving. Universities also interact with firms for diverse reasons and in diverse ways (Perkmann and Walsh, 2008). These include joint research, advisory work and contracts, and technology commercialisation, among others. Each of this wide array of interactions offers different opportunities to generate or disseminate knowledge. Firms choose the mode of interaction and their suitable university partner according to their specific needs and objectives. This further determines the impact of the UIC on the type of innovation that these interactions will nurture. Therefore, the outcomes of the university-industry interaction are diverse and the relationships may be non-linear and contingent (Gulbrandsen et al., 2011) depending on motivations and types of interactions between the university and the firm. Moreover, universities are of different types. The research capabilities of universities will have direct effects on the novelty of the innovation produced from a UIC, because innovation is path-dependent and the skills of researchers are the most important determinant of innovation.

The stage of development of an economy will influence the demand for external knowledge sources and the motivations of its firms to collaborate with universities. As a result, the behaviour and innovation impact of a UIC in an emerging economy such as China will be different from that in developed economies. On the demand side, since they are at an intermediate stage of development, the emerging economies have long been at a stage at which the assimilation of foreign technology has been a major source of technology upgrading and hence the priority was to absorb technology transferred from abroad (Hershberg, et al., 2007). As a result, universities in emerging economies are likely to engage more in the diffusion of frontier technology than the creation of such technology. Moreover, firms in latecomer economies have less R\&D and absorptive capacity (Eun, et al., 2006; 
Lee, et al., 2009). Owing to this constraint on the local industry, there is a need to tap into the expertise of science and engineering experts in universities to help with the assimilation and adaptation of foreign technology. Collaboration with universities will help to accelerate the adoption of foreign technology (Motohashi, 2005; Lyu, and Gunasekaran, 1993). This need for technical assistance in the economy will induce government policy responses that pull or even push the domestic universities to prioritise the problem-solving tasks as raised by the industry.

With regard to capabilities, the extent of development of an economy is often in line with the level of research capabilities of its universities and hence the type of innovation they are able/going to create. In Asian countries, universities began to pay more attention to research in recent decades, being prompted by government incentives (Hershberg, et al., 2007). The higher education sector in these countries is capable of collaborating with the industrial sector to assimilate the transferred foreign technology and make the adaptations necessary for foreign technology to fit within the local technical, economic and social context. Some alliances between industry and leading research universities are also capable of leading to a deep assimilation of foreign technology through reverse engineering and $R \& D$ to make modifications to the transferred foreign technology.

However, so far, the capability of domestic universities in China to carry out frontier research at the world level is still limited, except in a few subject areas at several elite research universities. For example, China's share in science and engineering articles has risen since the mid-1990s, accounting for 8.3 per cent of the global research output in 2009, next to that of the US. However, the quality of these papers as measured by the number of citations per paper was 5.87 in 2010, which was substantially lower than the world average at 10.57 (CSTII, 2010). The average number of citations per paper published by authors from the US, the Netherlands and the UK is about three times higher than that by the Chinese authors. This gap in the quality in published papers between authors from 
China and the world average exists in almost all subject areas except engineering technology and maths where the gap is relatively small. This gap in research capabilities and the concurrent high level demand for technical assistance from the private sector will lead to the rise of demand for knowledge from foreign universities.

Moreover, due to the heterogeneity of knowledge in different industries and in different locations, the supply of knowledge in one specific field in a given location may be limited even in advanced economies. This induces firms to look for knowledge from foreign sources. In the context of emerging economies, inflows of knowledge and technology from foreign sources have long been essential components of learning and innovation processes. International knowledge diffusion is therefore an important driver of economic growth (Coe and Helpman, 1995). External knowledge can be diffused between firms and across countries in several ways. These include international trade; inward and outward foreign direct investment; migration of highly skilled personnel; and integration into global value chains (Fu et al, 2011; Zucker and Darby, 2007).

Another possible channel for domestic firms to interact with international knowledge sources is to collaborate directly with foreign universities. In an open national innovation system, firms can collaborate not only with various domestic universities but also with foreign universities. Given the differences in research capabilities between domestic and foreign universities, firms in emerging economies may also collaborate with innovative foreign universities. The extent of the collaboration depends on the objectives of the mission, the research capability of the universities, the communication and financial capabilities of the firm, as well as the language, culture and geographic distance between the partners. Firms are technologically heterogeneous and their knowledge base is, as a whole, rather differentiated (Nelson and Winter, 1982). Talents and institutions with expertise in a particular field tend to cluster together (Auderstch and Feldman, 
1996). For firms in a particular industry, potential collaborators are limited in order to get cutting edge technology. As a result, firms may cross country borders to collaborate with foreign organisations, including foreign universities, for frontier research and innovation. In return, such cross border UICs are more likely to produce ground-breaking innovations due to a broader knowledge base and the input of leading researchers who have world-class expert knowledge in a particular area. Therefore, we have the following propositions:

H1a: Collaboration with domestic universities is likely to make a greater contribution to the diffusion of imitative innovation than the creation of ground-breaking novel innovations in China.

H1b: Collaboration between Chinese firms and foreign universities is likely to be associated with innovations of greater novelty.

\subsection{Cultural and technological distances and outcomes of international UICs}

The success of cross-border UICs will be dependent upon several factors which affect the knowledge exchange, integration and co-production process in addition to the research capability and absorptive capacity of partners (Cohen and Levinthal, 1990; Kodama, 2008). In the context of international UIC, differences in culture and technological capabilities as well as geographical distances may all affect the outcome.

Cultural differences. An innovation collaboration involves the integration of heterogeneous knowledge resources, which each of the partners possesses. This requires a wide range of cognition activities. It is found that the innovative performance of inter-firm alliances bears an inverted-U shaped function with cognitive distance and that an optimal cognitive distance depends on absorptive capacity (Nooteboom, et al., 2007). Cognition includes a broad range of mental activities, including proprioception, perception, sense making, categorisation, inference, value judgments, emotions, and 
feelings. National and organisational cultural differences are important factors that determine the cognitive distances between partners and hence the knowledge integration and co-production process. Although cultural distance may raise communication problems between partners, it is also argued to have a positive effect on international knowledge transfer due to an enlarged knowledge base (Vaara, et al., 2012). Distinguishing cultural differences at national and organisational levels, Sarala and Vaara (2010) find that national cultural differences are positively associated with knowledge transfer in international acquisitions. However, organisational cultural differences can have both negative and positive effects on knowledge transfer in acquisitions. A UIC often involves a formal collaboration between organisations. Therefore, cultural distance, especially organisational cultural distance, will affect the effectiveness of a UIC between Chinese firms and universities in the industrialised economies (Lin and Berg, 2001; Sirmon and Lane, 2004).

Technological distances. Technological distances between two parties involved in knowledge transfers are found to be an important factor for moderating the effectiveness of the transfer process. Some studies find that spillovers are present when technology gaps are moderate (Kokko et al, 1996). Girma and Gorg (2007) argue that the relationship between the technical gap and the strength of spillovers from foreign to local firms follows an inverted-U shape. Therefore, in the context of an innovation collaboration, a moderate technological gap between the collaborative partners is likely to result in maximum knowledge transfer and integration. Hence elite universities in other advanced developing countries such as the NIEs may be a better match for normal indigenous Chinese firms while universities in advanced economies may be a suitable match for the affiliates of multinational enterprises (MNEs) in China.

With regard to geographical proximity, evidence from the UK and the Netherlands suggests that firms give priority to quality of research over geographical proximity (Laursen, et. al., 2011) and that 
knowledge spillovers through a UIC are not limited to the regional scale (Ponds, 2010). Once such social, cultural and institutional connectors have been allowed for, MNEs are as likely to set up R\&D labs in nearby as in more remote locations (Castellani et al., 2013). Therefore, the influence of geographical distances on the performance of a UIC is limited.

Above discussions suggest that the effect of collaboration in innovation between Chinese firms and foreign universities is likely to be greater when the national cultural distance between the collaborating countries is larger, the organisational cultural distance is smaller, and the technological distance is moderate. Given the differences in culture, technology and market demand between Chinese firms and foreign universities in advanced and other developing economies, as well as the characteristics of indigenous and foreign invested firms in China, we have the following corollaries:

H2: Collaboration with foreign universities in the industrialised economies is likely to have a greater impact on innovation in foreign-invested firms in China than that in indigenous Chinese firms.

H2b: Collaboration with foreign universities in other advanced developing countries is likely to have greater impact on innovation in indigenous Chinese firms than that in foreign-invested firms in China.

\section{Methodology and data}

\section{Measurement}

Innovation outcome. Innovation could be measured in different ways, for example, R\&D expenditure, number of patents, or a dummy variable which equals 1 for innovation and 0 for no innovation based on firms' self assessment. Each has its advantages and limitations. In this study we use the sales of new or improved products as a measure of innovation output as this information is 
available in the survey dataset. In the survey, firms are asked whether, besides being new to their firm or the country, the innovation was also new to the world. This allows a distinction between innovations of the latter kind - which may be termed 'novel'- and innovations of the former kind which may be considered as 'imitative' innovations. Since we are interested in the different roles of universities in the creation of ground-breaking novel innovation and in translating, deciphering and adapting transferred foreign technology, we use two dependent variables: the proportion of sales accounted for by products which were ground-breaking at the world level, and, secondly, of those which were new to the country or firm. Although new product sales is the outcome of product innovation, research comparing the various innovation indicators finds that this indicator reflects, to a greater extent, a firm's overall innovation performance in both product and process innovations (Fu, 2012). Of course, this distinction of novel versus imitative innovation is based on firms' self assessment. The recognition of 'novel' innovation is subject to firms' knowledge of the new product and process development in the industry global-wise. Since some firms may not be fully aware of such information, there is a likelihood of overestimating the rate or proportion of 'novel' innovation in our sample. This is a limitation of the data that we should take into account when drawing up conclusions.

University-industry collaboration. Following the widely used proxy of inter-organisational collaboration in the literature, we consider a number of variables in an attempt to capture the direct university contribution to firms' innovation. We use a dummy variable that equals 1 if firms collaborated in any innovation activities with universities and public research institutions and 0 otherwise as a proxy for the presence of a UIC. We distinguish between universities located in a firm's own country, the NIEs, EU, US and Japan, and other countries to proxy the technological and cultural gap between the collaborators. Alternatively, we also include an indicator reflecting whether a firm cooperates with any other organisations, such as suppliers, customers, competitors, 
universities and PRIs, consultants and commercial labs in the course of its innovation activity. This allows for a direct test of the question as to whether a collaboration significantly influences a firm's innovation performance.

\section{Control Variables}

Intramural $\boldsymbol{R} \& \boldsymbol{D}$ expenditure and Extramural $\boldsymbol{R} \& \boldsymbol{D}$ expenditure of the firm: Investment in $\mathrm{R} \& \mathrm{D}$ is often found to be a significant determinant of innovation. Firms which engage in $R \& D$ are more likely to innovate because R\&D directly creates new products and processes and these firms are also more receptive to new external ideas. The size of extramural $R \& D$ is also important as a control over the effects of other type of collaborations, for example, with suppliers, customers, other firms in the same industry and within the company group.

Labour force skills: Labour force skills, especially qualified scientists and engineers, are another widely recognised critical factor that contributes to the innovation performance of firms (Hoffman et al, 1998). We use a dummy variable that equals 1 for firms reporting a lack of qualified personnel as being of medium and high importance and 0 for others as a control variable. Skills also enhance the firms’ absorptive capacity (Cohen and Levinthal, 1990).

Firm size: Larger firms have a greater range of market opportunities through which to exploit innovative opportunities. The size of the firm can therefore act as a proxy for this enhanced incentive to innovate. Larger firms also have greater resources for innovation.

Firm age: Older firms may have accumulated more experience and knowledge and be more capable in innovation. On the other hand, older firms may be constrained by organisational rigidity and hence be less active in innovation.

Industry specific effects: Since technological and innovation opportunities may occur unevenly across sectors, we include industry dummy variables to proxy for these effects. The full list of variables is summarised in Table 1 . 
Two estimation problems arise in this model. The first is that the dependent variable, the percentage of innovative sales, is constrained to a value between 0 and 100 and takes a value of zero in a large proportion of the sample. The Ordinary Least Squares (OLS) estimates would thus be biased. Therefore a Tobit model should be introduced to reduce the problem. The second problem is that a number of firms have not undertaken any $R \& D$ activity at all and therefore have no sales of new or significantly improved products. So there is a selection effect based on the decision to innovate or not. A Generalised Tobit (Hurdle) model needs to be employed to allow for the fact that firms decide either to innovate or not, and, with respect to those that are innovative, for the extent to which they are innovative (Mairesse and Monhen, 2002). As a robustness check, we also report the results from the standard Tobit model.

\section{Data}

This paper is based on our study of innovation in Chinese firms. We use a national innovation survey dataset of 1,408 manufacturing firms in China which was collected in 2008. This dataset contains data on firms' innovation activities over the 2005 to 2007 period. The survey was designed by Tsinghua University and implemented by the National Statistical Bureau. It covers 42 cities in China in both the coastal and inland regions of China. A total of 1,408 valid responses were received, with a response rate of 83.6 per cent. The questionnaire demonstrates high consistency and comparability with the design of the European Community Innovation Survey (CIS). The sample includes firms of all major ownership types that exist in China, and is composed of 9 per cent state or collectively owned enterprises, 7 per cent privately owned, 53 per cent share holding and limited liability companies, and 30 per cent foreign invested enterprises (FIEs) which are wholly-owned subsidiaries of MNEs or joint ventures in which foreign investment accounted for more than 25 per cent of total investment. The survey oversampled large and innovative firms. About 50 and 17.5 per cent of the 
firms in the sample are medium- and large-sized firms which have between 300 to 2000 and more than 2000 employees, respectively. The total reported R\&D investment in the sampled firms was RMB53350 million, accounting for 18.2 per cent of China's total R\&D investment in the manufacturing sector in 2007. After careful data cleansing to exclude observations with missing values for the necessary variables, the final dataset used in the estimation contains 802 firms, of which 95 per cent have innovated their products or processes. Therefore, the results of this study reflect the role of universities in the innovation of innovative Chinese firms rather than that in Chinese firms generally. This is a limitation of the research that we shall bear in mind when drawing conclusions.

In the questionnaire, firms are asked about their innovation outputs based on their self-assessment as well as their inputs into innovation such as intramural and extramural $R \& D$ expenditures and $R \& D$ personnel. With regard to innovation outputs, firms are asked to report whether in the past three years they have introduced any new product or production process. For firms that have introduced new products, they are also asked to report the proportion of their total sales in 2007 from products that are (1) new to the firm, (2) new to the country, and (3) new to the world. The firms are also asked about their innovation collaboration behaviour, eg. the type of their collaborators, which includes other firms in the company group, suppliers, customers, competitors, universities and PRIs, consultants and commercial labs. Information is also collected about the geographic location of these collaborators, which is divided into four groups mainly according to their technological advancement level as well as geo-economic links to China: (1) mainland China; (2) the fast growing NIEs nearby China including Hong Kong, Taiwan, Singapore and South Korea; (3) Innovation leaders such as Europe, the US and Japan; and (4) other countries. 
On average, nearly half of the surveyed Chinese firms report that they collaborated with external organisations ${ }^{1}$. Interestingly, universities and public research institutions are the most popular collaborator for Chinese firms, with 35 per cent of the firms reporting to have collaborated with them for innovation during the sample period. This is not surprising given that historically universities and public research institutions (PRIs) dominated the innovation system in China and there was a strong government policy of pushing the development of university-industry linkages. Most of the firms collaborate with Chinese universities. Around 3 per cent of the firms have collaborated with foreign universities. Amongst these foreign university collaborators, 51 per cent are from the US, Europe and Japan, 33 per cent are from the NIEs including South Korea, Singapore, Taiwan and Hong Kong, and 16 per cent are from other countries (Table 2). Chinese firms which have collaborated with foreign universities are mainly in the high- and medium-high technology industries. Although most of them are in the coastal region of China, there are still 37 per cent of the firms from the inland region. This is interesting, especially given that only 29 per cent of the firms in the sample are located in the inland region. Breaking down firms by ownership, domestic firms accounted for 65 per cent of all the firms that collaborated with foreign universities while FIEs accounted for 35 per cent. This is more or less consistent with the ownership distribution in the sample where FIEs accounted for 30 per cent of the firms in the sample.

\section{4. $\quad$ Results}

\subsection{What firms collaborate with foreign and domestic universities?}

We first run a Logit model to examine what kinds of Chinese firm collaborate with universities. We include in the model a vector of variables indicating a firm’s technological capabilities which will shape their collaborative activities. These include a firm's intramural and extramural R\&D

\footnotetext{
${ }^{1}$ The Chinese wording used in the survey ('he zuo') does not imply the subtle difference between collaboration and cooperation. Firms may regard both arms-length close cooperation and collaboration as being 'he zuo'. We therefore translate the wording into 'collaboration' which may include recursive and sustained interactions in addition to armlength cooperation. This may be a factor in the not small proportion of Chinese firms report having collaborated with external organisations for innovation.
} 
expenditure and human resources. Productivity level should also be an important determinant of a firm's collaborative activities. A firm of low level of productivity may not have the capacity to carry out collaborative innovation. However, since R\&D spending and human capital are two major sources of productivity and we have already included these variables in our regression, we decided not to include productivity into the regression to avoid (the problem of) multicollinearity ${ }^{2}$. We also include a vector of variables representing firm-specific characteristics such as size, age, industry and ownership. A dummy variable to represent a firm receiving government support for innovation is also included as an explanatory variable as this will enable a firm's financial capacity for collaborative research, especially as some government support schemes are specifically oriented to collaborative research.

Table 3 reports the estimated results of determinants of the UIC from the perspective of firms. Columns (1) and (3) show the estimated results of the determinants of collaboration with foreign and domestic universities, respectively. Firms which invested more in in-house R\&D activity show a greater propensity to collaborate with both domestic and foreign universities. However, extramural R\&D appears to be significantly associated with collaboration with domestic but not foreign universities. This is likely to be due to geographical proximity between domestic universities and Chinese firms, making extramural R\&D more feasible. Human capital also appears to be a significant factor in firms’ decisions to collaborate with universities, both domestic and foreign. The greater constraints in human capital a firm feels, the less the likelihood that a firm will engage in the UIC. Firm size does not appear to have a significant effect on firms’ propensity to collaborate with either domestic or foreign universities. Although large firms appear to be active in the UIC due to greater capabilities, small firms with some $R \& D$ activities are also found to engage in the UIC and benefit from such collaboration, for example in Japan (Motohashi, 2005). This is consistent with

\footnotetext{
${ }^{2}$ We have tested the regression with labour productivity included as one of the explanatory variables. The results are highly consistent with those reported in Table 3 although the estimated coefficients of the labour productivity variable are insignificant, probably due to the high correlation between productivity and R\&D and human capital.
} 
evidence from East Asia that firms with some R\&D activities, regardless of size, are willing to engage with the UICs (Lee, et a., 2009).

As the results in Column (1) indicate, younger firms such as start-ups are more likely to collaborate with foreign universities. Many of the young firms, especially those in the high-technology industry, are born with a global orientation (Filatotchev et al., 2009). A considerable proportion of their top management team have been educated, trained or worked abroad before they return to China. Young firms run by these returnees are more likely to collaborate with foreign universities than other firms. Government financial support on innovation does not appear to have a significant effect on firms' engagement with foreign universities. In contrast, as Column (2) shows, firms with government financial support are more likely to collaborate with domestic universities; this finding is statistically significant. This suggests that government $R \& D$ programmes, specifically designed to encourage university-industry linkages, have had a significant effect on the formation of such UIC linkages. Not surprisingly, foreign-invested firms collaborate significantly less with domestic universities than indigenous Chinese firms. This fact is consistent with the findings from an earlier survey among MNE affiliates in China (Zhou, 2006) and research in semi-conductor industries in China (Teece and Chesbrough, 2005). This may be explained by intellectual property considerations and the skill and capabilities mismatch between foreign invested firms in China and the Chinese universities.

\subsection{Foreign and domestic universities and innovation in the Chinese firms}

The estimated results of the role of universities in industrial innovation in China using the Generalised Tobit model corrected for potential selection bias are reported in Table $4^{3}$. Columns 1 to 3 report the regression results using the percentage of sales of products which are ground-breaking innovations in world terms as the dependent variable. Columns 4 to 6 report the results of regressions

\footnotetext{
${ }^{3}$ Estimated results of the first (selection) equation are reported in Appendix 1.
} 
using imitative innovations as the dependent variable. The results in columns (1) and (4) suggest that collaborations with other firms or institutions have a positive impact and are significantly associated with the creation of innovations that are new to the world and those which are new to the country/firm. The magnitude of the estimated coefficients is of similar size but those in the imitative innovation regression are of higher significance. However, treating all universities as a whole without distinguishing between the types of universities, the estimated coefficient of the 'collaboration with universities' dummy is not statistically significant, although bearing the expected positive sign. The creation of a single dummy variable to proxy the UICs between firms and different types of universities may have covered up the real and diversified picture taken place in reality. Moreover, as Chen and Kenney (2006) argue, although universities have formed an effective linkage and become a critical source for industrial innovations in some regions in China, such as Beijing, the fast growth of high-technology industries in many other regions is driven mainly by other sources.

Breaking down universities according to their country of origin, the estimated results exhibit some interesting findings in columns (3) and (6). Collaboration with domestic universities exhibits a positive but insignificant effect on novel innovation. This can probably be explained by the research quality of domestic universities in comparison to the world innovation frontier during the sample period (Guan and Ma, 2007; CSTII, 2010). However, the effect of imitative innovation is positive and statistically significant. The likely reasons are the priority given to technology transfer and assimilation in an emerging developing country like China, the incentives provided by the government that pushed universities to engage in many UICs for problem solving, and the current research capacity of the majority of the universities in the country. This is not only the case in hightechnology industries where universities helped with reverse engineering, but also in low-technology industries. For example, universities in Guangdong have played an active role with respect to imitative innovation in the textile and apparel industry ( $\mathrm{Li}$ and $\mathrm{Hu}, 2011)$. 
As expected, international innovation collaboration between Chinese firms and universities in the NIEs, namely Hong Kong, Taiwan, Singapore and Korea, appears to have a significant and positive effect on the generation of innovations by Chinese manufacturing firms. Internationally, joint scientific research between Chinese and foreign researchers has grown rapidly since the late 1990s. This is evidenced by increased joint publication which has benefited the research quality and impact of China (Guan and Ma, 2007). Scientific collaboration amongst Asian economies (in particular, China, Japan and Korea) has increased greatly since 1997. As a result, joint publication among authors from these countries has increased significantly since the late 1990s (Li et al., 2012). Moreover, the de facto active regional economic integration among business sectors and geographical proximity have also facilitated cross border collaboration between the Chinese firms and NIE universities. The active economic and scientific integration of the East Asian economies has thus resulted in productive UIC in the East Asian regional innovation system.

Moreover, firms that have innovation collaboration with universities in other countries (eg., Australia, Russia, Israel, India and Brazil) have a significantly higher proportion of sales accounted for by products which are new at the world level. As discussed earlier, despite the geographic and cultural distances between them, China and these countries share some common characteristics and interests because of their similar level of economic development. The similarity in stages of industrial development and the cultural diversity between the partners appear to have enabled a fruitful collaboration. Examples are the collaboration between Chinese firms and Australian universities in the solar Photovoltaic industry. Nevertheless, firms that collaborated with foreign universities in the 'other countries' group are concentrated in two industries: the communication equipment, computer and other electronic equipment manufacturing industry and special equipment manufacturing industry. These firms are very innovative: the average share of innovative sales in these firms is 72 
per cent, with 31 per cent accounted for by 'novel' innovations and 41 per cent for 'imitative' innovations. Such high industry concentration of this sub-sample may lead to an over-estimation of the impact of UIC with universities in countries other than NIEs, US, Europe and Japan. Therefore, we should be cautious about drawing strong conclusions on the general relationship between collaborations with universities in the 'other countries' group and novel innovation in Chinese firms.

Finally, linkages with universities in the major industrialised economies, i.e. US, Japan and Europe, although showing a positive effect, involve an estimated coefficient which is only marginally significant at the 10 per cent level. As discussed earlier, the compatibility of innovation capability of the elite Western universities and Chinese firms, their willingness to collaborate with each other, the significant organisational culture distance between the partners, the substantial differences in market demand and technical conditions between the partner countries, the absorptive capacity of the Chinese firms, the consideration of intellectual property protection on the Western partner side, and the lack of trust between the partners resulting from the above differences and concerns may all be responsible for the weaker significance in comparison to the effect of innovation collaboration between Chinese firms and the universities in the NIEs.

On the other hand, the significant effects of UIC with universities in NIEs in comparison with the weaker benefits from UIC with universities in the US/Europe/Japan may also be due to the differences in the characteristics of the firms that collaborated with them. As Table 2 indicates earlier, most of the firms that collaborated with universities in the NIEs are foreign owned firms in the high technology industries located in the coastal region. They have greater absorptive capacity, less organisational culture distance to the universities in the NIEs than those domestic firms in the inland regions and in the non-high technology sectors. Of the firms that collaborated with universities in the advanced industrial countries such as US and Europe, more than two thirds are domestic firms, more 
from the inland regions of China. Therefore, such differences in ownership, regional and industry composition between the firms that collaborated with universities in NIEs and advanced industrial countries give the 'demand' side explanation for why the UIC with universities in NIEs yield more novel innovations than that in the US and Europe.

Firms’ intramural $R \& D$ appears to be insignificantly associated with their sales intensity of novel products but is positive and significantly associated with their imitative innovation. This result is consistent with the work of Fu and Gong (2011) which examines the effect of indigenous R\&D activities on technology upgrading in China using a large firm-level panel dataset compiled by the National Statistical Bureau. As regards the other control variables, smaller firms appear to have a greater propensity for imitative innovation than larger ones. Moreover, younger firms appear to create more novel innovations. This may be partly due to the fact that some young start-ups are spinouts of universities which have novel technologies to commercialise. Moreover, some start-ups in China are born with a global background and orientation, with members trained overseas (Filatotchev et al., 2009). These young firms with links close to the global technology frontier (eg. the young high-technology firms in the ZhongGuanCun area) are more likely to create novel innovation.

Table 5 reports the results of a robustness check using the standard Tobit model. The estimated results are broadly consistent with the generalised Tobit model estimates, especially in respect to the pattern of the effect of different universities by country of origin. The effect of collaboration with domestic universities remains significant with respect to imitative innovation but not regarding novel innovation. International innovation collaboration with foreign universities in the NIEs and other developing countries all demonstrate a positive and significant effect. The estimated coefficients of the US/Japan/EU university collaboration dummy remain positive, but fall slightly from marginally 
significant to insignificant. In sum, the results on the role of different universities in industrial innovation are generally robust.

The collaboration variable is arguably determined simultaneously with the dependent variable of innovation. In other words, there might be a potential endogeneity problem. For example, firms that collaborate with other firms and universities are more likely to have more innovative sales. However, it is also possible that more innovative firms might collaborate to a greater extent with other firms and universities. Moreover, they are also more likely to be invited into any innovation collaboration by other organisations. In order to deal with the potential problem of endogeneity, we employ an instrumental variable regression technique to correct this problem. The instrumental variables used are all the exogenous variables in the model with the addition of two extra exogenous variables: a firm location dummy which indicates whether a firm is located in the six university concentrated cities; and a group dummy that equals 1 for firms that belong to a corporation group. Moreover, the use of industry dummies in the regressions is also designed to mitigate part of this potential endogeneity problem. We test whether the assumption of endogeneity is borne out by the data at hand. The Wald tests of exogeneity of the collaboration variables suggest there is no significant endogeneity problem. Therefore, the generalised Tobit model estimates are preferred to the instrumental variable model estimates. Consistent with the picture revealed in Tables 3 and 4, the effect of university collaboration remains insignificant for firm innovation, of both novel and imitative types ${ }^{4}$. Nevertheless, given the cross-sectional nature of the data and the difficulty of finding perfect instruments in practice, the relationship that can be inferred from the results is more one of association than causality.

\subsection{The role of universities in indigenous and foreign-invested firms}

\footnotetext{
${ }^{4}$ Due to space limitations, the estimated results are not reported here. They are available from the authors on request.
} 
Table 6 reports the estimated results of Hypotheses 2 concerning the different effects of foreign and domestic universities on novel innovation in indigenous Chinese and foreign-invested firms, respectively. Consistent with the pattern shown in Tables 4 and 5, the impact of domestic universities remains insignificant for both the indigenous and foreign-invested firms. As expected, collaboration with universities in the NIEs and in other developing countries bears a significant and positive impact on novel innovation in indigenous firms, which supports our Hypothesis 2b. The result is robust across models using different estimation methods. In contrast, the link with universities in the industrialised countries appears to have a significant positive impact on novel innovations in foreign invested firms, which supports our Hypothesis 2a. As discussed earlier, this is likely due to the reduced organisational cultural distances, moderate technological distance and a stronger absorptive capacity in the foreign-invested firms for the advanced technologies created in the US, EU and Japan. Evidence from this table also suggests that a moderate technological gap between partners and the absorptive capacity in the receiving firm is an important factor shaping the outcome of international UICs.

Intramural R\&D appears to be a significant driver of novel innovation in the indigenous firms. The magnitude of the estimated coefficient and the statistical significance are both higher than that in the larger sample which includes both indigenous and foreign invested firms. In contrast, the estimated coefficient of intramural R\&D is not significant for foreign-invested firms. This may be explained by the fact that affiliates of MNEs are often less active in frontier R\&D due to their linkage to, and reliance on, R\&D at their headquarters, as Table 3 indicates. Firm size and age however do not appear to have significant impacts on a firm's performance in creating important novel innovations in both indigenous and foreign-invested firms. Findings from this exercise, which distinguishes indigenous firms and MNE affiliates, are important because of their implications in collaboration partner selection for managers in both indigenous and MNE affiliates. Moreover, for development 
purposes, the innovation capacity of indigenous firms is a matter of special attention for policy makers in developing countries.

\section{Conclusions and Discussions}

This paper attempts to investigate the role of foreign and domestic universities in industrial innovation in emerging economies using a firm-level innovation survey database from China. The key findings of this study can be summarised as follows. First, international innovation collaboration with foreign universities benefits the creation of ground-breaking radical innovations in China although the best-matched partners vary between indigenous and foreign-invested firms. Second, collaboration with leading research universities in other developing countries, especially with those in the NIEs, such as Hong Kong, Taiwan, Singapore and Korea, appears to be fruitful in enhancing the creation of ground-breaking innovations in indigenous firms. Third, collaboration with universities in 'other countries', mainly the emerging South such as, Russia, Brazil and India, also appears to be positively associated with firms’ performance in radical innovation. Of course, given the small number of sampled firms that partnered with universities in 'other countries' and their high industry concentration in only two technology-intensive industries, we should be careful in drawing general conclusions on the gains from collaborating with universities in these countries based on current research. Nevertheless, our evidence does point out an alternative partnership other than the traditional partners for effective international innovation collaboration.

Fourth, collaboration with universities in the industrialised economies appears to be a significant external source of knowledge for foreign-invested firms in China. The US, Europe and Japan are the main home countries of foreign universities that engaged in innovation collaboration with Chinese firms. Firms that collaborated with them come from both high- and low-technology industries, in both coastal and inland regions of China. However, it does not appear to be as effective and fruitful 
for indigenous firms as expected. The gap in innovation capability between the elite Western research universities and Chinese firms, the significant organisational culture distance between the partners, the differences in market demand between the partner countries, the absorptive capacity of the Chinese firms, and the worry of weak intellectual property rights protection in China may all be responsible for the weaker significance of UIC between Chinese firms and universities in advanced industrial countries in comparison to that with the universities in the NIEs. At the same time, most of the firms that collaborated with NIE universities are foreign invested high technology companies located in the coastal region. These characteristics of Chinese partners also determined the higher absorptive capabilities and smaller cultural distances for the UIC between them and universities in the NIEs in comparison with those in the advanced industrial economies.

Finally, collaboration with domestic universities has played a significant role in the diffusion of frontier technology and the creation of imitative innovations, whiletheir contribution to the creation of ground-breaking innovations is limited in the current stage of development in China.

The overall pattern of the effectiveness of international UIC attests to the argument regarding the importance of cultural and technological distances between partners. A shared background in development stage and hence similar market demand for technology amongst the partners is important for effective international innovation collaboration. As a result, knowledge from universities in the NIEs appears to be more compatible and more relevant to Chinese indigenous firms to nurture novel and commercially relevant ideas. This is consistent with the argument of Acemoglu (2002) that technologies originated in the South are more appropriate for technological upgrading in the developing countries. 
Findings from the current research have important policy and practical implications for firms in both emerging and wider developing countries with regard to the processes involved in tapping into knowledge and resources from universities to promote innovation. Given the importance of technology transfer in developing countries, especially in the early stage of industrialisation, policies in the developing countries should greatly promote the UIC as a means of enhancing the absorptive capacity of the indigenous economy. Moreover, opening up the innovation system to enable domestic industries to collaborate with foreign universities should be an effective policy choice to promote radical innovation, especially for those emerging economies which are undergoing the crucial transformation from imitation to innovation. Domestic universities are best positioned to help firms in developing countries to assimilate, grasp, adapt and decipher transferred foreign technology.

Moreover, in their pursuit of greater novel innovation and catch-up, South-South collaboration appears to be a fruitful choice for indigenous firms in emerging economies. Increased economic integration and scientific collaboration have led to a closer relationship between Chinese firms and the universities of the NIEs. In these cases, the synergy, compatibility, and adequate technological gap between the two partners form a creative and knowledge-enriching basis from which innovative products and processes are co-produced. At the same time, collaboration with universities from the emerging South also appears to make a robust positive contribution to the production of novel innovations in indigenous firms. Therefore, firms in the developing countries seeking international collaboration should not constrain themselves by considering only universities in the several leading industrialised countries. Universities in other countries also present alternative opportunities supported with well targeted and selected collaborations.

Universities in major industrialised countries have been a useful knowledge source for novel innovation in foreign-invested firms in China, although they do not appear to benefit indigenous 
firms directly. This may be due to the stronger absorptive capability in the affiliates of MNEs and the smaller organisational cultural differences between the affiliates and the Western universities. If effective spillovers from foreign to domestic firms are present, foreign-invested firms can serve as a gatekeeper, tapping Western academic research into the Chinese economy. Moreover, as Chinese indigenous firms move up the technology ladder and converge with Western firms in terms of management culture and system in the future, they will be able to benefit more from a direct collaboration with universities in major industrialised countries.

It is important to acknowledge the limitations of our research. First, due to data limitations, our classification of cultural and technological differences is only roughly defined based on the grouping of countries. Better measurement of these gaps for each individual country instead of country group will provide more accurate insights on the moderating roles of cultural and technological distances in international knowledge transfer. Moreover, as discussed earlier, due to the possible endogeneity between collaboration and innovation and the limitations in data and instrumental variables, the relationship that can be inferred from the results is more one of association than causality. Finally, future research should take into account more detailed information regarding which university a firm has collaborated with and the research strength of the university in this particular discipline. Therefore, we do not consider this analysis to be the final word on the role of foreign and domestic universities in the emerging economies. 


\section{References}

Acemoglu, D.(2002) 'Directed Technical Change', Review of Economic Studies, Vol.69 No.4, pp.781-810.

Audretsch, D. B. and M. P. Feldman.(1996) 'R\&D spillovers and the geography of innovation and production', American Economic Review Vol.86 No.4, pp. 253-273.

Belussi, F., Sammarra, A. and Sedita, S. R.(2010) 'Learning at the boundaries in an "Open Regional Innovation System”: A focus on firms' innovation strategies in the Emilia Romagna life science industry’, Research Policy, Vol.39 No.6, pp.710-721.

Bjorkman, I., Stahl, G. K. and Vaara, E.(2007) 'Cultural differences and capability transfer in crossborder acquisitions: the mediating roles of capability complementarity, absorptive capacity, and social integration', Journal of International Business Studies, Vol.38, pp.658-672.

Braczyk, H.J., Cooke, P., Heidenreich, M. (eds).(1998) Regional Innovation Systems: The Role of Governance in a Globalized World, UCL Press, London.

Castellani, D., Zanfei, A. and Jimenez, A.(2013) 'How remote are R\&D labs? Distance Factors and International Innovative Activities', Paper presented at the Reading-UNCTAD International Business Conference, Reading University, UK.

Chen K., Kenney M.(2007) 'Universities/Research Institutes and Regional Innovation Systems: The Cases of Beijing and Shenzhen', World Development, Vol.35 No.6, pp.1056-1074.

Chesbrough H.(2003) Open Innovation: The New Imperative for Creating and Profiting from Technology Harvard Business School Press, Boston, Massachusetts.

China Science and Technology Information Research Institute (CSTII).(2010) Statistical data of Chinese Science and Technology Papers. CSTII, Beijing, China.

Coe, D. and Helpman, E.(1995) 'International R\&D spillovers', European Economic Review, Vol.39 No.5, pp. 859-887.

Cohen, W. M. and Levinthal D. A.(1990) 'Absorptive Capacity: A New Perspective on Learning and Innovation’, Administrative Science Quarterly, Vol.35 No.1, pp.128-152.

Eom B-Y., Lee K.(2010) 'Determinants of industry-academy linkages and, their impact on firm performance: The case of Korea as a latecomer in knowledge industrialization', Research Policy, Vol.39 No.5, pp. 625-639.

Etzkowitz, H.(2002) MIT and the rise of entrepreneurial science, Routledge, London.

Eun J-H., Lee K., and Wu G.S.(2006) 'Explaining the "University-run enterprises” in China: A theoretical framework for university-industry relationship in developing countries and its application to China', Research Policy, Vol.35 No.9, pp.1329-1346.

Filatotchev, I., Liu, X., Buck, T. and Wright, M.(2009) 'The export orientation and export performance of high-technology SMEs in emerging markets: The effects of knowledge transfer by returnee entrepreneurs', Journal of International Business Studies, Vol.40, pp.1005-1021.

Fu, X. and Gong, Y.(2011) 'Indigenous and foreign innovation efforts and drivers of technological upgrading: evidence from China’, World Development, Vol. 37 No.9, pp. 1213-1225.

Fu, X., Pietrobelli, C. and Soete. L.(2011) 'The role of foreign technology and indigenous innovation in emerging economies: technological change and catch-up', World Development, Vol.39 No.7, pp.1203-1212.

Fu, X. (2012) 'How Does Openness Affect the Importance of Incentives for Innovation?', Research Policy, Vol.41, No. 3, 512-23.

Girma, S. and Görg, H.(2007) 'The role of the efficiency gap for spillovers from FDI: Evidence from the UK Electronics and Engineering Sectors', Open Economies Review, Vol.18 No.2, pp.215-232.

Goes, J.B. and Park, S.H.(1997) 'Interorganizational links and innovation: the case of hospital services’, Academy of Management Journal, Vol.40 No.3, pp.673-696. 
Guan, J. and Ma, N.(2007) 'China's emerging presence in nanoscience and nanotechnology: A comparative bibliometric study of several nanoscience 'giants', Research Policy, Vol.36 No.6, pp. 880-886.

Giuliani, E. and Rabellotti, R.(2012) 'Universities in emerging economies: bridging local industry with international science-evidence from Chile and South Africa', Cambridge Journal of Economics, Vol.36 No.3, pp. 679-702.

Gulbrandsen, M., Mowery, D. and Feldman, M.(2011) 'Heterogeneity and university-industry relations', Research Policy, Vol.40 No.1, pp.1-5.

Hershberg, E., Nabeshima, K. and Yusuf, S.(2007) 'Opening the Ivory tower to business: universityindustry linkages and the development of knowledge-intensive clusters in Asian cities', World Development, Vol.35 No.6, pp. 931-940.

Hoffman, K., Parejo, M., Bessant, J. and Perren, L.(1998) 'Small firms, R\&D, technology and innovation in the UK: a literature review', Technovation, Vol.18 No.1, pp.39-73.

Kaufmann, A. \& Todtling, F.(2001) 'Science-industry interaction in the process of innovation: the importance of boundary-crossing between systems', Research Policy, Vol.30 No5, pp.791-804.

Keupp, M. M., and Gassmann, O.(2009) 'Determinants and archetype users of open innovation', $R \& D$ Management, Vol.39 No.4, pp.331-341.

Kodama, T.(2008) 'The role of intermediation and absorptive capacity in facilitating universityindustry linkages-An empirical study of TAMA in Japan', Research Policy, Vol.37 No.8, pp. $1224-1240$.

Kokko, A., Tansini R. and Zejan M.C.(1996) 'Local technological capability and productivity spillovers from FDI in the Uruguayan manufacturing sector', Journal of Development Studies, Vol.32 No.4, pp.602-611.

Lai, Wen-Hsiang.(2011) 'Willingness-to-engage in technology transfer in industry-university collaborations', Journal of Business Research, Vol. 64 No.11, pp. 1218-1223.

Laursen, K., Reichstein, T. and Salter, A.(2011) 'Exploring the Effect of Geographical Proximity and University Quality on University-Industry Collaboration in the United Kingdom', Regional Studies, Vol.45 No.4, pp.507-523.

Laursen, K. and Salter, A.(2006) 'Open for innovation: the role of openness in explaining innovation performance among UK manufacturing firms’, Strategic Management Journal, Vol.27 No.2, pp.131-150.

Lee, K.; Joseph, K.J.; Eun, J.-H., Rasiah, R.; Wu, G.; Schiller, D. et al.(2009) Promoting Effective Modes of University-Industry Interaction and their Evolution for Economic Catch-up in Asia, Final Research Report, East Asia Institute.

Li, L. and Hu, G.(2011) 'Imitative innovation: a sensible choice for the innovation in higher and polytechnic universities', Jiaoyan Lilun, No.3, pp.16-20. (In Chinese)

Li, J., Xiong, H. and Zhang, S. and Sorensen, O.J.(2012) 'Co-authorship patterns in East Asia in the light of regional scientific collaboration', Journal of Science and Technology Policy in China, Vol. 3 No. 2, pp.145-163.

Lin, B. and Berg, D.(2001) 'Effects of cultural difference on technology transfer projects: an empirical study of Taiwanese manufacturing companies', International Journal of Project Management, Vol.19 No.5, pp.287-295.

Lyu, JrJung and Gunasekaran, A.(1993) 'Implementation of advanced manufacturing technology through industry-government-university’, Computers in Industry, Vol. 22 No.2, pp. 187-192.

Mairesse, J. and Mohnen, P.(2002) 'Accounting for innovation and measuring innovativeness: an illustrative framework and an application', American Economic Review Papers and Proceedings, Vol. 92 No. 2, pp.226-230.

Motohashi, K.(2005) 'University-industry collaborations in Japan: The role of new technology-based firms in transforming the National Innovation System', Research Policy, Vol. 34 No.5, pp. 583594. 
Mowery, D. C. and Sampat, B.N.(2005) 'Universities in National Innovations Systems' In Fagerberg, F., Mowery, D, Nelson, R (ed.) The Oxford Handbook of Innovation, New York, Oxford University Press, Oxford.

Mowery, D. C., Oxley, J. E. \& Silverman, B. S.(1996) 'Strategic alliances and inter firm knowledge transfer’, Strategic Management Journal, Vol.17 Special issue, pp.77-91.

Nelson R.R. and Winter S.(1982) An Evolutionary Theory of Economic Change, The Belknap Press of Harward University Press, Cambridge, Massachusetts.

Nooteboom, B.(2009) A cognitive theory of the firm; Learning, governance and dynamic capabilities, Edward Elgar, Cheltenham UK.

OECD.(2008) National Innovation System in China, OECD, Paris.

Perkmann, M , Walsh, K.(2008) 'Engaging the scholar: Three types of academic consulting and their impact on universities and industry’, Research Policy, Vol.37 No.10, pp.1884-1891.

Ponds, R., van Oort, F. and Frenken, K.(2010) 'Innovation, spillovers and university-industry collaboration: an extended knowledge production function approach', Journal of Economic Geography, Vol. 10 No.2, pp.231-255.

Powell, W. W. \& Grodal, S.(2005) 'Networks of Innovators' in Fagerberg, F., Mowery, D, Nelson, R. (ed.) The Oxford Handbook of Innovation New York, Oxford University Press, Oxford.

Sarala, R. M. and Vaara.(2010) 'Cultural differences, convergence, and crossvergence as explanations of knowledge transfer in international acquisitions', Journal of International Business Studies, Vol.41, pp.1365-1390.

Sirmon, D. G. and Lane, P.J.(2004) 'A model of cultural differences and international alliance performance', Journal of International Business Studies, Vol.35, pp.306-19.

Teece, D. and Chesbrough, H. W.(2005) Globalisation of $R \& D$ in the Chinese semiconductor industry, Report to the Alfred P. Sloan Foundation.

Tsai, W.(2001) 'Knowledge transfer in intra organizational networks: effects of network position and absorptive capacity on business unit innovation and performance', Academy of Management Journal, Vol.44 No.5, pp. 996-1004.

Vaara, E., Sarala, R., Stahl, G. K. and Bjorkman, I.(2012) 'The impact of organisational and national cultural differences on social conflict and knowledge transfer in international acquisitions', Journal of Management Studies, Vol.49 No.1, pp.1-27.

Wu W.P.(2007) 'Cultivating Research Universities and Industrial Linkages in China: the Case of Shanghai’, World Development, Vol.35 No.6, pp.1075-1093.

Yusuf, S.(2008) 'Intermediating knowledge exchange between universities and businesses', Research Policy, Vol.37 No.8, pp. 1167-1174.

Zhang, Y.(2009) 'Alliance-based network view on Chinese firms' catching-up: case study of Huawei Technologies Co Ltd.’, UNU-MERIT, working paper 2009-039.

Zhou, Y.(2006) 'Features and impacts of the internationalisation of R\&D by transnational corporations: China's case' in Globalisation of $R \& D$ and Developing Countries, New York and Geneva: UNCTAD, United Nations.

Zucker, L. G. and Darby, M. R.(2007) 'Star Scientists, Innovation and Regional and National Immigration’, NBER Working Paper No. 13547. 
Table 1 Definition of variables and descriptive statistics

\begin{tabular}{|c|c|c|}
\hline Variable & Definition & Mean \\
\hline newsal & $\%$ of new sales & 33.970 \\
\hline newsaln & $\%$ of sales of products that are ground-breaking in world terms ('novel') & 5.134 \\
\hline newsald & $\begin{array}{l}\% \text { of sales of products that are new to China or the firm or are significantly } \\
\text { improved ('imitative') }\end{array}$ & 29.312 \\
\hline lrdin & Ln(intramural R\&D expenditure) & 5.135 \\
\hline lrdex & Ln(extramural R\&D expenditure) & 0.906 \\
\hline size & Firm size dummy equally 1 for large firm and 0 for small firm. & 0.675 \\
\hline age & Firm age & 16.705 \\
\hline lack_hc1 & $\begin{array}{l}\text { Human capital constraints dummy variable, } 1=\text { the importance of lack of } \\
\text { qualified personnel to innovation is medium and high; and } 0=\text { low or } \\
\text { unimportant }\end{array}$ & 0.822 \\
\hline со & Innovation cooperation dummy variable, $1=$ yes, $0=$ no & 0.483 \\
\hline cogd & $\begin{array}{l}\text { Dummy variable, } 1=\text { cooperate with other firms within an enterprise group; } \\
0=\text { no }\end{array}$ & 0.291 \\
\hline cosd & Dummy variable, $1=$ cooperate with suppliers; $0=$ no & 0.305 \\
\hline cocd & Dummy variable, $1=$ cooperate with customers; $0=$ no & 0.296 \\
\hline copd & $\begin{array}{l}\text { Dummy variable, } 1=\text { cooperate with competitors or other firms in the same } \\
\text { industry; } 0=\text { no }\end{array}$ & 0.212 \\
\hline coprid & Dummy variable, $1=$ cooperate with private R\&D institutions; $0=$ no & 0.179 \\
\hline counid & $\begin{array}{l}\text { Dummy variable, } 1=\text { cooperate with universities and public research institutions } \\
\text { (PRIs); } 0=\text { no }\end{array}$ & 0.353 \\
\hline couni1 & Dummy variable, $1=$ cooperate with universities and PRIs in China; $0=$ no & 0.343 \\
\hline $\begin{array}{l}\text { couni2 } \\
\text { couni3 } \\
\text { couni4 }\end{array}$ & $\begin{array}{l}\text { Dummy variable, } 1=\text { cooperate with universities and PRIs in Newly } \\
\text { Industrialised Economies (Hong Kong, Taiwan, Singapore, Korea); } 0=\text { no } \\
\text { Dummy variable, } 1=\text { cooperate with universities and PRIs in Europe, US and } \\
\text { Japan; } 0=\text { no } \\
\text { Dummy variable, } 1=\text { cooperate with universities and PRIs in other countries not } \\
\text { listed above; } 0=\text { no }\end{array}$ & 0.016 \\
\hline
\end{tabular}


Table 2. Distribution of foreign university collaborators in China

\begin{tabular}{lcccc}
\hline \multicolumn{4}{c}{ Home country of the foreign universities } & \\
\hline & NIE & EU\&US\&JP & Other countries & $\begin{array}{c}\text { Total foreign } \\
\text { university }\end{array}$ \\
\hline By industry & & & & \\
Low\&medium-low tech & $7 \%$ & $12 \%$ & $0 \%$ & $19 \%$ \\
High\&medium-high tech & $26 \%$ & $40 \%$ & $16 \%$ & $81 \%$ \\
Total & $33 \%$ & $51 \%$ & $16 \%$ & $100 \%$ \\
& & & & \\
By region & & & & \\
Inland & $7 \%$ & $19 \%$ & $7 \%$ & $33 \%$ \\
Coastal & $26 \%$ & $33 \%$ & $9 \%$ & $67 \%$ \\
Total & $33 \%$ & $51 \%$ & $16 \%$ & \\
& & & & \\
By ownership & & & & \\
Domestic owned firms & $19 \%$ & $35 \%$ & $12 \%$ & $35 \%$ \\
Foreign owned firms & $14 \%$ & $16 \%$ & $5 \%$ & $100 \%$ \\
Total & $33 \%$ & $51 \%$ & $16 \%$ & \\
\hline
\end{tabular}

Source: Authors' estimation based on the 2008 China innovation survey. 
Table 3. Determinants of university-industry collaboration in China

\begin{tabular}{|c|c|c|c|c|}
\hline & \multicolumn{2}{|c|}{ Co-with foreign university } & \multicolumn{2}{|c|}{ Co-with domestic university } \\
\hline & Coef. & Std. Err. & Coef. & Std. Err. \\
\hline Ln(intramural R\&D exp) & $0.206^{*}$ & 0.115 & $0.192 * * *$ & 0.043 \\
\hline Ln(extramural R\&D exp) & 0.062 & 0.064 & $0.117 * * *$ & 0.030 \\
\hline Firm size & -1.628 & 1.033 & -0.335 & 0.238 \\
\hline Firm age & $-0.043^{* * *}$ & 0.016 & 0.004 & 0.006 \\
\hline Constraints in human capital & $-0.829 *$ & 0.492 & $-0.458 *$ & 0.273 \\
\hline Co-with domestic uni & 0.590 & 0.688 & & \\
\hline Co-with foreign uni & & & 0.560 & 0.831 \\
\hline Foreign-invested firm dummy & 0.246 & 0.578 & $-1.304^{* * *}$ & 0.246 \\
\hline Government support & 0.766 & 0.591 & $1.273^{* * *}$ & 0.220 \\
\hline Industry dummies & yes & yes & yes & yes \\
\hline Constant & yes & yes & yes & yes \\
\hline Observations & 592 & & 592 & \\
\hline Log likelihood & -74.690 & & -295.939 & \\
\hline
\end{tabular}

Notes: Robust standard errors are reported here. ${ }^{* * *} \mathrm{p}<0.01,{ }^{* *} \mathrm{p}<0.05,{ }^{*} \mathrm{p}<0.1$. 
Table 4. Universities and firm innovation in China: Generalised Tobit model estimates

\begin{tabular}{|c|c|c|c|c|c|c|}
\hline & \multicolumn{3}{|c|}{ Novel innovation } & \multicolumn{3}{|c|}{ Imitative innovation } \\
\hline & 1 & 2 & 3 & 4 & 5 & 6 \\
\hline \multirow[t]{2}{*}{ co with other org. } & 2.3 & & & $6.250 * *$ & & \\
\hline & $(1.442)$ & & & $(2.824)$ & & \\
\hline \multirow[t]{2}{*}{ co with universities } & & 2.111 & & & 3.967 & \\
\hline & & $(1.414)$ & & & $(2.786)$ & \\
\hline \multirow[t]{2}{*}{ co with domestic uni. } & & & 1.045 & & & $5.239 *$ \\
\hline & & & $(1.402)$ & & & $(2.779)$ \\
\hline \multirow[t]{2}{*}{ co with uni in NIEs } & & & $12.09 * *$ & & & -0.693 \\
\hline & & & $(5.914)$ & & & (11.99) \\
\hline \multirow[t]{2}{*}{ co with uni in US/EU/Japan } & & & $8.429 *$ & & & -8.014 \\
\hline & & & $(4.696)$ & & & $(9.338)$ \\
\hline \multirow[t]{2}{*}{ co with uni in other countries } & & & $17.08 * *$ & & & -5.956 \\
\hline & & & $(8.088)$ & & & (15.87) \\
\hline \multirow[t]{2}{*}{ Ln(intramural R\&D exp) } & $0.409 *$ & 0.357 & 0.267 & $2.308 * * *$ & $2.331^{* * *}$ & $2.329 * * *$ \\
\hline & $(0.213)$ & $(0.224)$ & $(0.227)$ & $(0.427)$ & $(0.453)$ & $(0.45)$ \\
\hline \multirow[t]{2}{*}{ Ln(extramural R\&D exp) } & & 0.105 & 0.119 & & 0.197 & 0.108 \\
\hline & & $(0.185)$ & $(0.184)$ & & $(0.363)$ & $(0.363)$ \\
\hline \multirow[t]{2}{*}{ Firm size } & 0.729 & 0.856 & 0.397 & $-5.874 * *$ & $-5.220 *$ & $-5.732 *$ \\
\hline & $(1.502)$ & $(1.498)$ & $(1.501)$ & $(2.962)$ & $(2.968)$ & $(2.979)$ \\
\hline \multirow[t]{2}{*}{ Firm age } & $-0.053 *$ & $-0.056 *$ & -0.048 & -0.021 & -0.024 & -0.040 \\
\hline & $(0.030)$ & $(0.030)$ & $(0.030)$ & $(0.058)$ & $(0.059)$ & $(0.059)$ \\
\hline \multirow[t]{2}{*}{ constraints in human capital } & -0.205 & -0.468 & -0.484 & -4.728 & $-5.600 *$ & $-6.201 * *$ \\
\hline & $(1.613)$ & $(1.573)$ & $(1.557)$ & $(3.171)$ & $(3.104)$ & $(3.112)$ \\
\hline Industry dummies & yes & yes & yes & yes & yes & yes \\
\hline Constant & yes & yes & yes & yes & yes & yes \\
\hline Observations & 817 & 817 & 817 & 802 & 802 & 802 \\
\hline Log Likelihood & -3366 & -3367 & -3354 & -3815 & -3819 & -3813 \\
\hline
\end{tabular}


Table 5. Robustness check: Tobit model estimates

\begin{tabular}{|c|c|c|c|c|c|c|}
\hline & \multicolumn{3}{|c|}{ Novel innovation } & \multicolumn{3}{|c|}{ Imitative innovation } \\
\hline & 1 & 2 & 3 & 4 & 5 & 6 \\
\hline co with other org. & $\begin{array}{l}10.40^{* *} \\
(5.111)\end{array}$ & & & $\begin{array}{c}9.828^{* * *} \\
(3.321)\end{array}$ & & \\
\hline co with universities & & $\begin{array}{c}5.344 \\
(5.205)\end{array}$ & & & $\begin{array}{c}4.276 \\
(3.513)\end{array}$ & \\
\hline co with domestic uni. & & & $\begin{array}{c}1.345 \\
(5.094)\end{array}$ & & & $\begin{array}{l}5.954^{*} \\
(3.532)\end{array}$ \\
\hline co with uni in NIEs & & & $\begin{array}{c}35.67 * * * \\
(11.25)\end{array}$ & & & $\begin{array}{l}-5.64 \\
(17.1)\end{array}$ \\
\hline co with uni in US/EU/Japan & & & $\begin{array}{c}17.29 \\
(10.72)\end{array}$ & & & $\begin{array}{l}-13.58 \\
(11.04)\end{array}$ \\
\hline co with uni in other countries & & & $\begin{array}{c}35.32 * * \\
(15.97)\end{array}$ & & & $\begin{array}{l}-8.254 \\
(16.5)\end{array}$ \\
\hline Ln(intramural R\&D exp) & $\begin{array}{c}2.106^{* *} \\
(0.865)\end{array}$ & $\begin{array}{c}1.299 \\
(0.937)\end{array}$ & $\begin{array}{c}1.203 \\
(0.921)\end{array}$ & $\begin{array}{c}2.949 * * * \\
(0.544)\end{array}$ & $\begin{array}{c}3.007^{* * *} \\
(0.589)\end{array}$ & $\begin{array}{c}2.929 * * * \\
(0.595)\end{array}$ \\
\hline Ln(extramural R\&D exp) & & $\begin{array}{l}1.623^{* *} \\
(0.649)\end{array}$ & $\begin{array}{c}1.690 * * * \\
(0.647)\end{array}$ & & $\begin{array}{c}0.0666 \\
(0.46)\end{array}$ & $\begin{array}{l}0.0009 \\
(0.461)\end{array}$ \\
\hline Firm size & $\begin{array}{c}5.967 \\
(5.553)\end{array}$ & $\begin{array}{c}4.837 \\
(5.673)\end{array}$ & $\begin{array}{c}3.428 \\
(5.642)\end{array}$ & $\begin{array}{l}-3.446 \\
(3.728)\end{array}$ & $\begin{array}{l}-5.144 \\
(3.932)\end{array}$ & $\begin{array}{l}-5.629 \\
(3.912)\end{array}$ \\
\hline Firm age & $\begin{array}{l}-0.257 \\
(0.159)\end{array}$ & $\begin{array}{l}-0.244 \\
(0.168)\end{array}$ & $\begin{array}{c}-0.202 \\
(0.161)\end{array}$ & $\begin{array}{c}-0.0266 \\
(0.0575)\end{array}$ & $\begin{array}{c}-0.024 \\
(0.0603)\end{array}$ & $\begin{array}{l}-0.0467 \\
(0.0622)\end{array}$ \\
\hline constraints in human capital & $\begin{array}{l}-1.933 \\
(5.134)\end{array}$ & $\begin{array}{l}-2.811 \\
(5.171)\end{array}$ & $\begin{array}{l}-2.645 \\
(5.067)\end{array}$ & $\begin{array}{l}-2.605 \\
(3.63)\end{array}$ & $\begin{array}{l}-6.097 \\
(3.874)\end{array}$ & $\begin{array}{l}-6.154 \\
(3.869)\end{array}$ \\
\hline Industry dummies & yes & yes & yes & yes & yes & yes \\
\hline Constant & yes & yes & yes & yes & yes & yes \\
\hline Observations & 928 & 817 & 817 & 910 & 802 & 802 \\
\hline F statistics & 6.293 & 5.218 & 5.73 & 7.746 & 5.116 & 3.445 \\
\hline Log Likelihood & -1454 & -1298 & -1291 & -3741 & -3320 & -3314 \\
\hline
\end{tabular}


Table 6. Universities and novel innovation in indigenous and foreign-invested firms

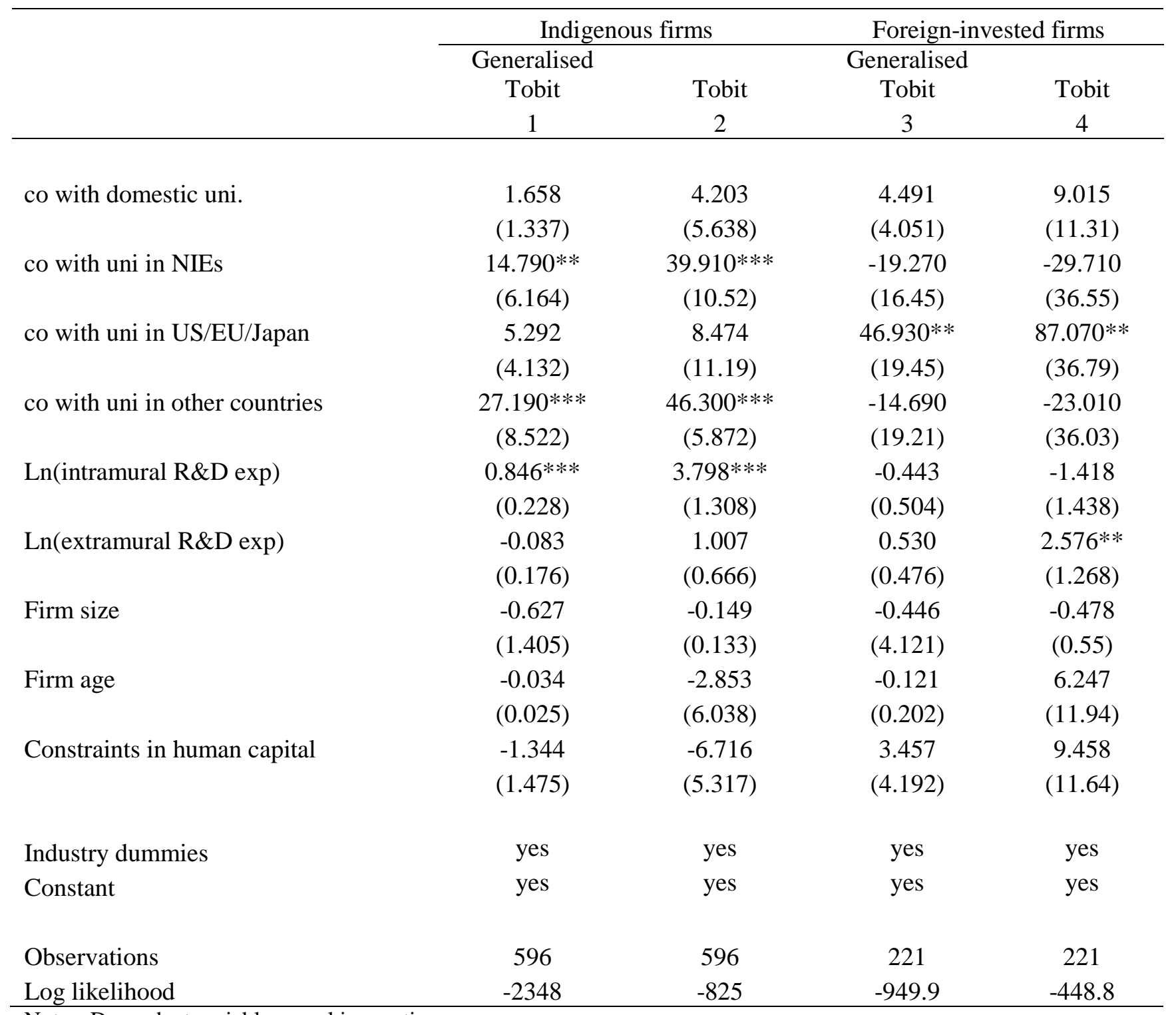

Notes: Dependent variable: novel innovation.

Robust standard errors in parentheses. ${ }^{* * *} \mathrm{p}<0.01,{ }^{* *} \mathrm{p}<0.05,{ }^{*} \mathrm{p}<0.1$ 
Appendix. Results of the selection equation of the Generalised Tobit model

\begin{tabular}{lcc}
\hline & Novel innovation & Imitative innovation \\
\hline Ln(intramural R\&D exp) & $0.163^{* *}$ & $0.113^{* * *}$ \\
& $(0.067)$ & $(0.004)$ \\
Ln(extramural R\&D exp) & 10.820 & 0.008 \\
& $(229.50)$ & $(0.009)$ \\
Firm size & 0.617 & -0.061 \\
& $(0.413)$ & $(0.040)$ \\
Firm age & 0.009 & 0.001 \\
& $(0.008)$ & $(0.002)$ \\
Constraints in human capital & -0.190 & $-0.147^{* * *}$ \\
& $(0.578)$ & $(0.050)$ \\
Industry dummies & Yes*** & Yes*** \\
Constant & Yes & Yes \\
& & 802 \\
Observations & 817 & -3813 \\
Log Likelihood & -1288 & \\
\hline
\end{tabular}

Notes: Robust standard errors in parentheses. ${ }^{* * *} \mathrm{p}<0.01,{ }^{* *} \mathrm{p}<0.05,{ }^{*} \mathrm{p}<0.1$.

Results reported here are that of the selection equations of the full model for the whole sample. 